DOI: $10.28934 /$ jwee18.12.pp17-30

SCIENTIFIC REVIEW

\title{
Employment Women Through Entrepreneurship Development and Education in Developing Countries
}

\author{
Priscilla Achakpa ${ }^{1}$ \\ Water Supply and Sanitation Collaborative Council, Abuja, Nigeria \\ Mirjana Radović-Marković ${ }^{2}$ \\ Institute of Economic Sciences, Belgrade, Serbia
}

\begin{abstract}
A B S T R A C T
Women entrepreneurship is today one of the major factors contributing to a country's prosperity and to the global market in general. However, females still own and manage significantly fewer businesses than men. Especially, women in developing countries face disadvantages and discrimination. Compared to their male counterparts, women in developing countries have a lower level of education and skill training. Another important challenge for female entrepreneurs in developing countries is the issue of safety and protection of women, especially those operating in the informal economy. The most female entrepreneurs in developing economies are motivated to start their businesses out of necessity, reflecting lack of employment alternatives or dissatisfaction with existing employment. The overall nature and extent to which female entrepreneurship can develop in developing economies is greatly influenced by project to strengthening them. In line with this, the aim of our research was to explore the impact of one of these programmes - GWIN project and its effect to empowering women in Nigeria. Based on the findings, it was concluded that GWiN project plays a significant role in the economic development of women in Nigeria through the benefits of various supports to them.
\end{abstract}

\footnotetext{
Executive Director of Women Environmental Programme, Nigeria, e-mail: pmachakpa@gmail.com

${ }^{2}$ Prichilla`s Ph. D mentor, e-mail: mirjana.radovic@ien.bg.ac.rs
} 
KEY WORDS: female entrepreneurship, empowerment, education support project, Nigeria

\section{Introduction}

Women's well-being is determined by self-esteem and harmony in relationships. Radović-Marković, Nelson-Porter and Omolaja (2009) defined entrepreneurship as the formation of entrepreneurial affiliations, which planned to guarantee the improvement of crucial economic, social, and different changes in rural areas through people making innovations and governmental systems frameworks concocting a provincial improvement strategy in light of putting resources into rural entrepreneurship.

Major challenges facing the Nigerian women include:

Cultural boundaries - As in many other countries, Nigerian has conservative traditional values and customs in doing business activities. Cultural beliefs remain an obstacle in hindering women from being entrepreneurs in Nigeria.it has been misconcepted that entrepreneurship is a business for men, whereas women should stay home and be housewives. Nigeria is also a patriarchal society as it is mentioned, "the asymmetry and ascendency of makes over female in the labor market are clearly seen in patriarchal communities, whereas in Nigeria there is a large power distance and high masculinity. This cultures form a barrier for Nigerian women entrepreneurs and are growing under unjust cultures and male dominated society. Lack of access to finance - Another major limitation to women entrepreneurs is that they experience lack of access to finance.

Studies by Vossenberg (2013) for instance, reveal that African women do not possess the necessary skills to adapt to the impact of globalization, evolving technologies and changing patterns of trade. Vocational training has become an important source for forming entrepreneurial ability in women and often age, experience and background can compensate for lack of formal education in the success of the venture. In their research GarciaCabrera \& Garcia-Soto (2008) also found that women in developing countries rely more than their counterparts in developed countries on extended families which, in many rural settings are often their only or major social network. This is often constraining since their decisions and incomes many times become dependent on different people, which also limit their ability to take risk, diversify and/or innovate. The benefits of entrepreneurial learning are multifaceted. Entrepreneurship education can, from a young 
age, awaken entrepreneurial spirit and can foster a positive attitude towards independence, risk-taking and learning from failure for females engaged in entrepreneurial activities resulting in a boost for other females who intend to participate in same.

The growing number of initiatives aimed at promoting entrepreneurship and empowering women in developing countries reflects a generally growing interest in the role played by entrepreneurship in the economic development process.

The aim of this study was to examine the methodological impact of GWiN project for strengthening women economic empowerment in Nigeria. Many researchers have tried to capture this based on their individual studies, but they were limited to their own kind of study for example study have been done both internationally (India and Kenya) and locally (Ondo and Nasarawa). Further opportunities can surface by studying impact of GWiN Project for strengthening women economic empowerment in Africa with focus on Nigeria.

\section{Theoretical Overview}

Many reviews have been led on women business visionaries with reference to different nations. So, Nachimuthu and Gunatharan (2012) analyzed the enterprise of women they thought to be a successful instrument to the financial advancement and strengthening of women. The Self improvement Gatherings is thought to be institutional advancement that cultivates strengthening of financially and socially denied women. The review by Nachimuthu and Gunatharan (2012) talks about the contrasts between women in different types of endeavors and the Self improvement gatherings, and endeavors to distinguish the quality of these two types of venturesome in engaging women. In another review, Huntley (1985) utilized a contextual investigation way to deal with investigate the life occasions and encounters that had impacted women to pick business enterprise as a vocation elective. Most wandered into enterprise due to a craving to be free and to be in control of their lives.

Rahman and Naoroze (2007) led a review on women strengthening through support in aquaculture in Bangladesh. The creators utilizing various regression investigations watched that of the five chose measures of strengthening; access to resources and assets alone was in charge of 59.8\% of the variety in general strengthening. The aftereffect of the review 
utilizing different relapse investigation uncovered that lone four autonomous factors were noteworthy indicators of women's strengthening. These were investment in aquaculture (represented 14.9\%), instruction (represented 9\%), expansion media contact (represented 4\%) and preparing (represented 2.5\%) of varieties in strengthening. A huge relationship was found between women's training and their strengthening which suggests that instruction upgrades women's strengthening both in the family and the general public.

Upadhye and Madan (2012) analyzed business enterprise and women's empowerment: Confirmation from Pune City. As per the authors, women from the lower strata of the general public however taught, cannot discover work in urban India. It is enterprise that clears the way of advancement of these women specifically and society all in all. The review considers women from such lower strata of society transforming into business people in city of Pune, Maharaastra India. The review depicts a photo of change in the identity, monetary and economic wellbeing of women from the lower strata of the public. The authors make an endeavor to profile the same with the advancement of a record. The review reasons that there is a stamped change in the identity, the financial and the societal position of these ladies. The outcomes are observed to be factually noteworthy. In any case, the reality remains that abilities, profit, respect, work proficiency and even the raised monetary status of women business people require not really change the approach of society towards women. The male predominance in the public arena is hesitant to change their state of mind towards women.

Sathiabama (2010) in his review expressed that strengthening of women has risen as a vital issue as of late. The monetary strengthening of women is being viewed nowadays as a Sine-quo-non of advance for a nation; henceforth, the issue of financial strengthening of women is of fundamental significance to political masterminds, social researchers and reformers. The Self-improvement Gatherings (SHGs) have made ready for monetary autonomy of provincial women. The individuals from SHGs are included in Small scale - Business enterprises. Through that, they are turning out to be financially autonomous and giving work chances to others. The writer in his article manages strengthening of country women through business enterprise and the points of interest business among the rustic women.

Strengthening of women must be accomplished if their monetary and societal position is made strides. The review expressed this could be 
conceivable just by receiving unequivocal social and monetary arrangements with a perspective of aggregate advancement of women and to make them understand that they can possibly be solid individuals. Be that as it may, so as to make a reasonable world, we should start to enable women. Likewise, proposed that need ought to be given to the training of women, which is the grassroots issue and mindfulness programs should be composed for women. At long last, the review infers that entrance to instruction; business and change in social structure are just the empowering elements to women strengthening in the review range.

Ovute, Dibia and Obasi (2015) in their endeavor to re-accentuate and re-stir the brain of mankind on the undisputable part of women in national improvement portrayed women strengthening as the arrangement of sufficient chances to women to build up their possibilities and add to the advancement of the country specifically and the world when all is said in done. As indicated by the researchers women have been sabotaged since creation. Endeavors made so far towards women strengthening has yielded little organic products. The creators in this way analyzed difficulties obstructing Nigerian women's successful commitment to national advancement, parts of women in national improvement, endeavors made so far towards women strengthening and how Nigerian women could be enabled to add to national advancement. The paper at last recommended that since the part of ladies in national improvement is vital in the advancement of any nation, the Nigerian government owes it as an obligation to evacuate those counterfeit and institutional hindrances in view of religion, culture, or conventional contemplations which have cripple Nigeria women in taking an interest adequately and uninhibitedly in national undertakings especially, at the political and financial levels so they will contribute their standard to National advancement among others.

Ejumudo (2013) made an evaluation of the level of achievement of sexual orientation equality and women strengthening utilizing three basic pointers to be specific: enrolment in training at the essential, auxiliary and tertiary levels, business and political basic leadership, used important optional wellsprings of information. The writer contended that, at the heart of the risky of sex dissimilarity in Nigeria, is the activity situation by the Nigerian government which has intensified the issue of extending the limit level that is required to upgrade the chance of pleasing the fluctuating needs of both male and female sexual orientation additionally fights that the fulfillment of sex correspondence in Nigeria which is now time-banished, 
will be a hallucination due to multi-dimensional compelling variables. The author pivoted the completion of sexual orientation uniformity and women strengthening on tile allure and certainty of a down to business approach, presumed that building up a sex well-disposed and sex touchy society that is without all remnants of segregation and disparity in order to outfit the true abilities of every single social gathering and advance the standards of major human rights is the pushed of the Thousand years Improvement Objective of Sex Equity and women Strengthening. Accomplishing the above objective is not just fundamental for supportable advancement endeavors in Nigeria: it likewise requests a down to business way to deal with fitting approach definition, program configuration, centered usage and compelling checking and assessment in an agreeable atmosphere of political will, bona fide duty and national re-introduction.

Ibrahim (2013) analyzed women strengthening in the north-eastern part of Nigeria making utilization of two direct pointers in light of optional information acquired from the 2008 Nigerian Statistic Wellbeing Study. The specialist concentrated on the north-east geopolitical zone comprising of six states viz; Adamawa (1018), Bauchi (1008), Borno (990), Gombe (1005), Taraba (1217) and Yobe (979). A sum of 6217 women were met in this zone. Likewise, he uncovered that far under half of women in the north-east geopolitical zone of Nigeria can settle on choices on a few issues of significance in the family units. He proceeded with that local settings of women (urban/rural) influence the level of acknowledgment of spouse beating, such less rate of women living in urban district of the north-east Nigeria concur with the idea of wife beating for some other reason, while more noteworthy rate of physical assault was found in the country women. The examination gave a conclusion that women's level of instruction apparently was in a roundabout way relative to the avocation of spouse beating for the expressed reasons. That is, women with no instruction concur with the idea more than the ladies having advanced education.

Ibrahim, Zumilah and Laily (2013) directed a review on enabling provincial young women through instruction: Method for decreasing powerlessness and enhancing family financial prosperity in rural Northern Nigeria with an emphasis on Katsina State. As indicated by the researcher, there is recorded confirmation that larger part of rural young ladies in Northern Nigeria does not finish elementary school talk less of auxiliary schools and tertiary foundations. These demonstrate that the rural young ladies are falling behind instructively. The issue is the need to teach the 
young girl child and young women in the provincial territories of the nation on the grounds that rural women are the biggest and helpless gathering. There are four key components distinguished for enabling rustic young ladies and young ladies; subjective, asset control, social capital, and mindfulness or access to data. These essential components have been analyzed on the prosperity of ladies among the groups of the enabled country young women through quantitative review utilizing organized survey. Examination of these surveys indicates solid positive relationship between the training strengthening and their monetary prosperity level and huge contrast $(\mathrm{p}<.005)$ in their lives. The review adds light to comprehension effects of teaching young ladies and ladies for family and group success and dismissing these can prompt to the backwardness. It is additionally some portion of developing assortment of writing from provincial sub-Sahara Africa on sex issue. It adds to the future review on comparable subjects.

Adekanye (2014) inspected data needs, usage and financial strengthening of material market ladies in Southern Nigeria. An overview examine plan and purposive testing system were embraced for the review. Two Geo-political Zones in Nigeria were chosen. Discoveries of the review demonstrated that there was a relative impact of data needs, looking for, sources, and use on the financial strengthening of the material market women. It was likewise found that data looking for has the most astounding critical impact on the financial strengthening of the material market women. Alongside this was data sources and distinguishing proof of data needs. However, data utilize had no noteworthy impact. The outcome showed that the Nigerian material market women were inventive, alterable and imaginative in their entrepreneurial exercises when they are enabled with data, which constantly would bring self-maintainability and societal advancement. In view of the discoveries, it was presumed that the data conduct of Nigerian material market women as far as requirements, looking for, and sources have huge impact on their financial strengthening.

Kelly (2013) inspected sexual orientation equity and women strengthening in Nigeria. He made an appraisal of the level of fulfillment of women strengthening and sex equality utilizing three basic markers to be specific: enrolment in instruction at the essential, optional and tertiary levels, business and political basic leadership, used profitable auxiliary wellsprings of information. The main marker uncovered that MDGs report appears there is change in regard of achieving widespread fundamental 
training and the essential six consummation rate expanded altogether from 65 percent in 1998 to 83 percent in 2001; it declined in 2002 and expanded again to 94 percent in 2003 and 95percent in the vicinity of 2004 and 2005. In any case, enrolment at the elementary school level has reliably been higher for young men who have 56 percent contrasted and the 44 percent for young ladies. Second marker likewise uncovered accomplishment of MDGs in regard of sexual orientation uniformity and women's strengthening is business. Women association in the mechanical part is evaluated at $11 \%$ contrasted and the $30 \%$ for men. Additionally, in the Government Common Administration, which is the biggest single-element business in Nigeria, $76 \%$ of government employees are men and $24 \%$ are women. In the interim, women constitute fewer than $14 \%$ of the aggregate administration level positions, while $17.5 \%$ of those occupied with the therapeutic field are women contrasted and the $82.5 \%$ men. What is more, the last marker uncovered the achievement of sex equality in accordance with the thousand years Advancement Statement is association in political basic leadership. As indicated by him, the proportion of ladies association in basic leadership is $38.2 \%$ contrasted with men $61.8 \%$. In his discoveries, he found the imperatives in completing sexual orientation correspondence and women strengthening in Nigeria; patriarchal culture, defilement, mal-administration and false open speculation, insufficient limit, political will and honest to goodness duty. Likewise found routes in which sexual orientation uniformity and women strengthening in Nigeria can be completed; friendly atmosphere, investment and organization by legislative and nonadministrative partners, socio-social re-introduction, political will and honest to goodness duty and satisfactory human, institutional and infrastructural limit. He presumed that administration at all levels in agreeable association with different partners in Nigeria needs to venture up endeavors so that calculable advance could be accomplished in a formative approach.

Osirike and Egbayebo (2012) inspected the participatory part of women in group advancement in the country territories in Ilaje, Ondo State. The scientist clarified that Ilaje Nearby Government Region of Ondo State was the objective populace for the review. It included the choice of groups from each of the four kingdoms that constituted the Nearby Government Region. In light of this approach, 3 groups each was browsed both Ugbo and Mahin kingdoms; while 2 groups each were looked over both Etikan and Ahasi kingdoms individually. 15 women each were spoken to the 6 groups chose from both Ugbo and Mahin Kingdoms, though 10 respondents each were 
spoken to the 4 groups chose from both Etikan and Aheri kingdoms separately. In light of arbitrary inspecting, 130 ladies chose from ten (10) groups in Ilaje neighborhood government zone of Ondo State, Nigeria.

The researcher credited the low support of women in group advancement endeavors to poor level of instruction and absence of part displaying among the women. His discoveries uncovered that there is a huge relationship between the instructive status of rural women and their interest in group advancement and to guarantee viable investment in group improvement, the study suggested that women in the provincial zones ought to be given the fundamental training with a specific end goal to upgrade their adequacy in group advancement ventures. They ought to likewise be given the correct consolation, good and material backings on the grounds that without these backings, any projects being set out upon would yield insignificant effect.

Vimal and Gagandeep (2016) analyzed sex balance and women strengthening in India. In their investigation, they expressed that sexual orientation fairness and women's strengthening is human rights that lie at the heart of improvement and the accomplishment of the thousand years Advancement Objectives.

Research by Garcia-Cabrera and Garcia-Soto (2008) has shown that when it comes to generating innovative business ideas, the environment in poor countries is such that women, in particular, face very high opportunity costs for turning attention away from pressing matters to seek or perceive new business opportunities. The same research reveals that for households at subsistence level may be unacceptable to assume the high risk of exploiting opportunities subject to uncertainty as the potential losses may outweigh the potential gains.

Employment of women in the informal sector has risen rapidly in the developing world. In her research Radovic-Markovic (2009) found that the estimated size of this sector of the economy goes up to $50 \%$ in developing countries, making up $48 \%$ of the non-agricultural employment in NorthAfrica, 51\% in Latin America, 65\% in Asia and 72\% in Sub-Saharan Africa. This growth however, has taken place in the context of an unemployed and underemployed population with very limited social support, particularly for poor women (Radovic-Markovic, 2013).

In recent years a new area of research has been gaining interest as the prevailing method to foster rural development, particularly in regions with inadequate infrastructure, low levels of education and low incomes. Rural 
entrepreneurship is the creation of entrepreneurial associations that will ensure crucial economic, social and other changes in rural regions and improve these regions (Radovic-Markovic, 2009). As such, rural entrepreneurship represents a very significant employment opportunity for women of rural communities who can work near home, improving their earnings and elevating their standards of living. However, national policies and programs to aid development, as well as education and empowerment of women must take place in order for these types of enterprise development to succeed.

\section{Research Methodology}

The methodology of the study was an integration of quantitative and qualitative methods based on data collected from four villages of Meskan Woreda. Five key indicators of empowerment covering five dimensions were chosen for this purpose. Data were collected from 120 respondents during June-August 2013. Finally, Women empowerment in agriculture index (WEAI) was developed adding the obtained scores of five empowerment indicators. Descriptive statistics and regression analysis were used to analyze the collected data. The regression analysis shows that there were strong positive effects of age, formal and non- formal education, information through media exposure, farm income, training and extension service on the empowerment, while socio-economic status in the agricultural communities have a strong negative effect.

\section{Key Findings and Discussion}

This research has been limited to six-political zones in Nigeria. The aim of this study was to examine the methodological impact of G-WIN project for strengthening women economic empowerment in Nigeria. This research was limited to five objectives which are; evaluate the extent of awareness of the G-WIN project in Nigeria, examine the G-WIN projects implementation as a basis for strengthening women economic empowerment in the study area, investigate the constraints on the implementation of the G-WIN project to strengthen women economic empowerment in the study area, investigate the constraint or hindrances that might pose a threat to replicating the G-WIN to other parts of the world and examine the extent to which institutional framework plays out in 
strengthening women economic empowerment in Nigeria and in other countries.

The study was justified by the gap it fills in literature. Most studies in this area have been offshore. Past researchers both within the country and various part of the world had undergone research on this study, but none has undergone such on Growing Women and Girls in Nigeria (GWIN).

In achieving the aim of this project, effort was made through questionnaire, physical observation and phone calls to obtain the most reliable information for this study. Questionnaire was administered to 2400 Beneficiaries of GWIN Project but 1934 were retrieved, 120 copies of questionnaire were administered to Pioneer Ministries but 114 were retrieved. The information obtained was analyzed according to the objectives of this study. Objective 1: to evaluate the extent of awareness of the G-WIN project in the study area. Different means of awareness were evaluated using frequency distribution for both the Beneficiaries and the Pioneer Ministries both respondents admitted that GWIN Project gets to the ears of the public was through the use of local government support. Objective 2: to examine the G-WIN projects implementation as a basis for strengthening women economic empowerment in the study area. Diverse forms of basis were examined in this study using frequency distribution. After comparing responses from both Beneficiaries and Pioneer Ministries, findings confirmed that most of the basis which the project has emulated to touch the lives of women in the study area was majorly through skills acquisition. Objective 3: to investigate the constraints on the implementation of the G-WIN project to strengthen women economic empowerment in the study area.

Various forms of constraints were investigated using frequency distribution, findings reveals majority of respondents confirmed that all (insufficient fund, cultural belief and low turnout) these challenges are the limitations to GWIN Project. Objective 4: to investigate the constraint or hindrances that might pose a threat to replicating the G-WIN to other parts of the world. Various forms of constraints the Project is likely to encountered were investigated using frequency distribution, findings reveal that most of the respondents thought that most of the challenges that GWIN Project is likely to face if replicated to other parts of the world are insecurity, insufficient funds, corruption, gender disparity and nongovernmental acceptance. Objective 5: to examine the extent to which institutional framework plays out in strengthening women economic 
empowerment in Nigeria and in other countries. Various forms of institutional framework were examined using frequency distribution, findings reveal most respondents admitted that mostly all the institutional framework (enlighten the populace, socio-cultural re-orientation, genial climate, participation and partnering by governmental and nongovernmental stakeholders and women political will) plays out in strengthening women economic empowerment in the study area.

Based on these findings, it is recommended that: conferences, seminars and workshops should be organized for women in the study area so as to give them an in-depth knowledge about what participation economic development entails current trade in Computer Technology, such as computer appreciation should be introduced, while active participation in politics by women should be promoted.

The women in the area should be given the necessary education (they deserve) in order to enhance their effectiveness in economic development projects. It will also promote the empowering of women towards achieving one of the Growing Women and Girls in Initiative Nigeria (GWIN) 2014.

Women should be selected from the various communities for training as trainee trainers. These women should be appointed later as extension officers or community development officers so that they can as well train others and help them to solve their communal problems.

\section{Acknowledgements}

This paper is part of the research projects number 47009, Ministry of Science and Technological Development of the Republic of Serbia.

\section{Conclusion}

Considering the importance of entrepreneurship for empowering women, it is pertinent that our educational institutions (both formal and informal) step up to the challenge of helping our females to develop their entrepreneurial acumen towards sustainable development of livelihoods and the economy at large. In view of the foregoing, we recommend the following;

1. Women should be given equal opportunities to showcase their skills and abilities, and this could be effectively enhanced when they are adequately educated 
2. Technology comes exposure, it is amazing how so many female entrepreneurs are still keeping their head in the sand about using the most basic technological aid. It is important that female entreprenuers in order to foster their business must be knowledgeable about the different technologies that would enhance their business and here the role of education in is key

3. "Women entrepreneurs play a substantial role in growing their economies. When a country does not achieve its full potential, the economy suffers. Fewer 'high potential' female entrepreneurs result in fewer ideas being realized, less innovation, less export potential, and fewer jobs created," the report said.

4. "Through their entrepreneurial activities, female entrepreneurs increase their own economic welfare and generate job creation, innovative products, processes, and services, and cross-border trade.

\section{References}

[1] Adekanye, E. 2014. Information needs, utilization and socio-economic empowernment of textile market women in Southern Nigeria. Library Philosophy and Practice (e-journal), 1093: 1-22

[2] Ejumudo, K.B. 2013. Gender equality and women empowerment in nigeria: The desirability and inevitability of a pragmatic approach. Developing Country Studies, 3(4): 59-67.

[3] Huntley, R. L. 1985. Women entrepreneurs and career choice. Dissertation Abstracts International.

[4] Garcia-Cabrera, A.M. \& Garcia-Soto, M. 2008. Cultural differences and entrepreneurial behavior: An intra-country cross-cultural analysis in Cape Verde. Entrepreneurship and Regional Development, 20(5): 451-483.

[5] Ibrahim, A. 2013. Women's empowerment in North-Eastern Nigeria and factors affecting it. International Journal of Innovative Research and Studies, 3(1): 36-48.

[6] Ibrahim, A., Zumilah, Z., \& Laily, B. P. 2013. Empowering rural girls through education: way of reducing vulnerability and improving family economic wellbeing in rural Northern Nigeria, IOSR Journal of Humanities And Social Science (IOSR-JHSS), 18(1): 57-61.

[7] Kelly, B. E. 2013. Gender equality and women empowerment in Nigeria: The desirability and inevitability of a pragmatic approach. Developing Country Studies, 3(4): 59-67. 
[8] Nachimuthu, S.S., \& Gunatharan, B. 2012. Empowering women through entrepreneurship: A study in Tamil Nadu, India. International Journal of Trade, Economics and Finance, 3(2): 143-147.

[9] Osirike, A.B., \& Egbayebo, T.E. 2012. Women empowerment for community development in Nigeria. JORIND, 10 (3), 5-11.

[10] Ovute, A.O., Dibia, N. G., \& Obasi, S.C. 2015. Empowering Nigerian women for national development: State of the art, challenges and prospects. Journal of Research in Business and Management, 3(1): 04-10.

[11] Radović-Marković, M., Nelson-Porter, B. L., \& Omolaja, M. 2009. The new alternative women's entrepreneurship education: e-learning and virtual universities. Journal WOJDE (July 2012 ed.). Retrieved from http://wojde.org/FileUpload/bs295854/File/complete.wojde.pdf on 18th February, 2017

[12] Radovic-Markovic, M. 2009. Women entrepreneurs: New opportunities and challenges. Delhi, India: Indo-American Books

[13] Radovic-Markovic, M. 2013. Female Entrepreneurship: Theoretical Approaches. Journal of Women's Entrepreneurship and Education, 1-2: 1-9.

[14] Rahman, M. H., \& Naoroze, K. 2007. Women empowerment through participation in aquaculture: experience of a large-scale technology demonstration project in Bangladesh. Journal of Social Science, 3(4): 164171.

[15] Sathiabama, K. 2010. Rural women empowerment and entrepreneurship development. eSS Student Papers.

[16] Upadhye, J., \& Madan, A. 2012. Entrepreneurship and women empowerment: Evidence from Pune City. International Conference on Economics, Business and Marketing Management, 29, pp. 192-197.

[17] Vimal, V., \& Gagandeep, S. 2016. Gender equality and women empowerment in India. International Journal of Multidisciplinary Research and Development, 3(12): 112-116.

[18] Vossenberg, S. 2013. Women Entrepreneurship Promotion in Developing Countries: What explains the gender gap in entrepreneurship and how to close it? (Working paper No. 2013/08). Retrieved from www.msm.nl/getattachment/e94b7b38-e17b-4c5d-b497-c4135be7ec86

Article history: Received: 14 March, 2018

Accepted: 31 May, 2018 